\title{
Evidence of Detection of High-Energy Microwave Radiation in Electronic Equipments
}

\author{
György Györök \\ Óbuda University, Alba Regia Technical Faculty, \\ Budai Str. 45, 8000 Székesfehérvár, Hungary \\ gyorok.gyorgy@amk.uni-obuda.hu
}

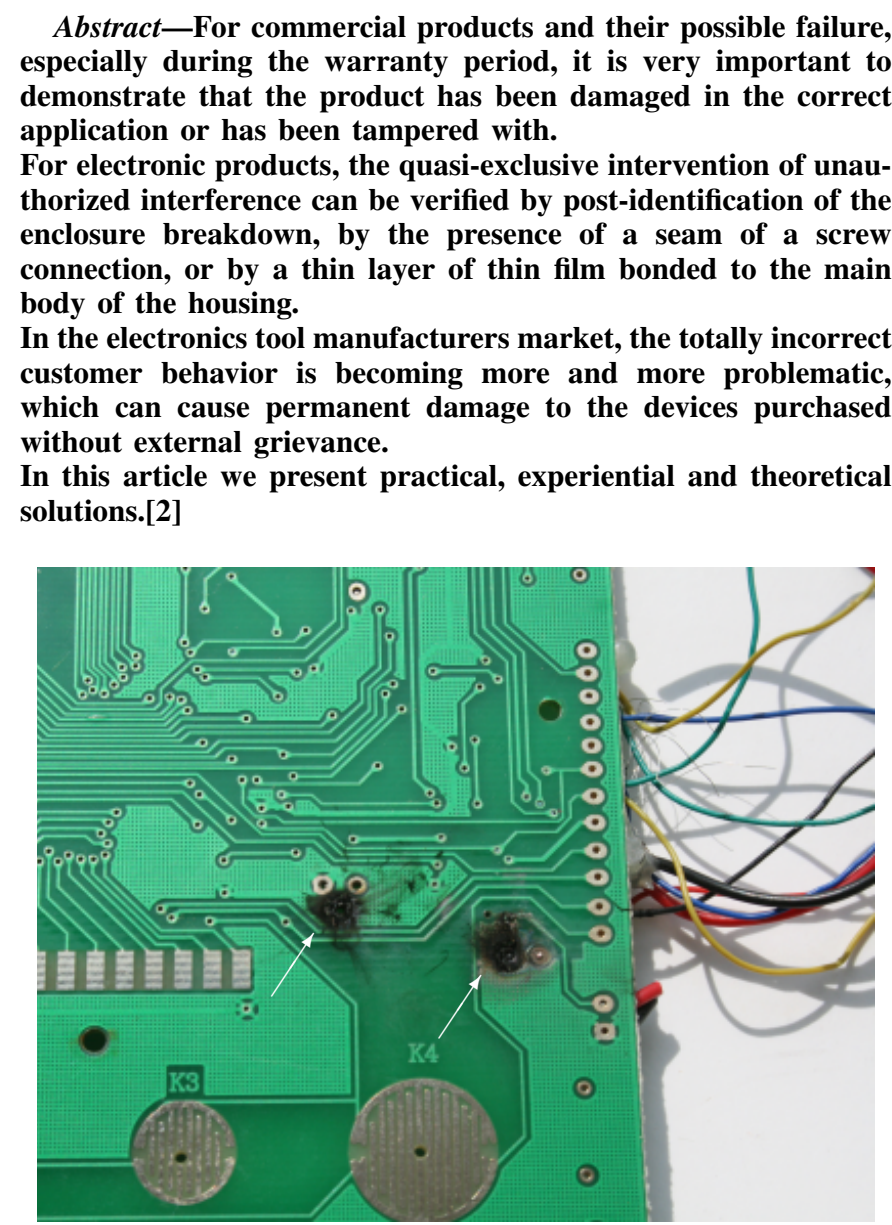

Fig. 1. Burns of phenomenal of microwave energy on surface of FR4 type two sided printed circuit board.

\section{INTRODUCTION}

One of the most commonly occurring occurrences is that a broken or tapping device is placed in a microwave oven for a few seconds with microwave energy. Consequently, it is often not detectable, or only in a verifiable way, to damage certain internal components, wires, isolations of printed circuits (Fig.1-3), integrated circuits (Fig.4), components (Fig.5), internal structural elements. On figures there are damage points are indicated by white arrows. [11] [9] [6]

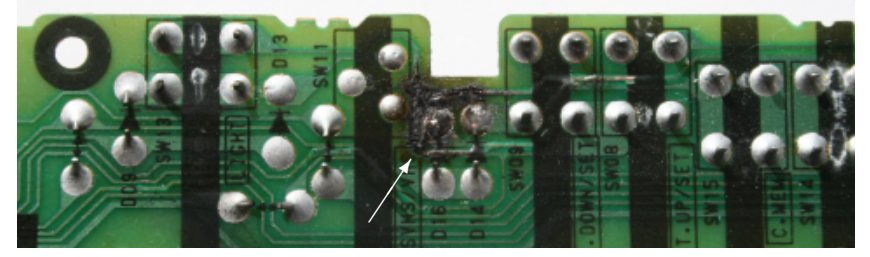

Fig. 2. urns of phenomenal of microwave energy on surface of paper phenol type one sided printed circuit board.

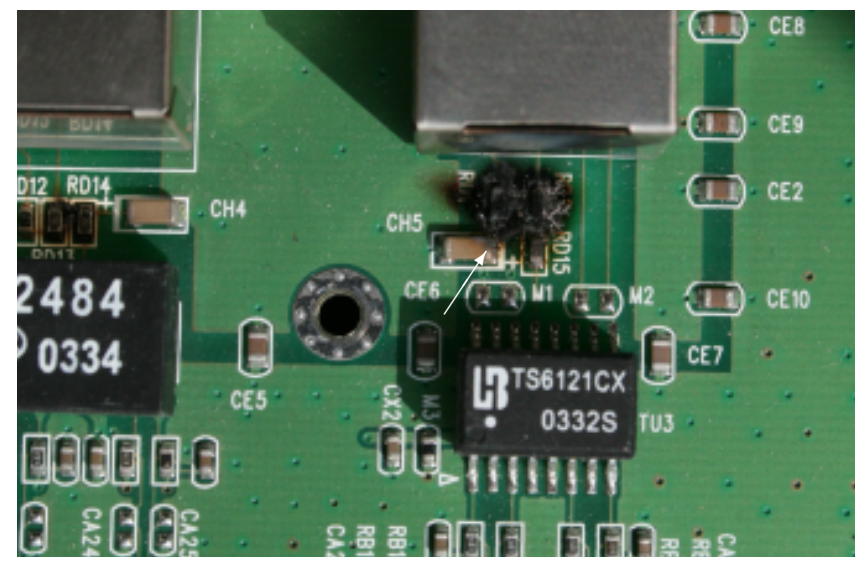

Fig. 3. Cracking an package of an LSI circuit at irradiation of $800 \mathrm{~W}$ for $4 \mathrm{~s}$.

High-energy microwave radiation generates electrical voltages on all efficient antenna-like surfaces, wires. Nearly one kilowatt power enough big to can generate hundreds of volts in one of the radiated antenna loads. Of course, a printed circuit board, its wiring and components are most likely to form an effective antenna. The component or insulation at the output of antennas will damaged [12].

Damage can be basically two types; electrical breaks or electric shorts. Electrical break is generated by the high current, which flowing through the conductor (copper foil of PCB, pin to pin gold wire, strip of silicon); the conductor (metal, coal, graphite) sublimates [1].

\section{DAMAGE BY MICROWAVE ENERGY}

The magnetron of household microwave ovens oscillates at about $2.4 \mathrm{GHz}$ frequency $\left(f_{\mu W}=2,4 G H z\right)$. The power of these 


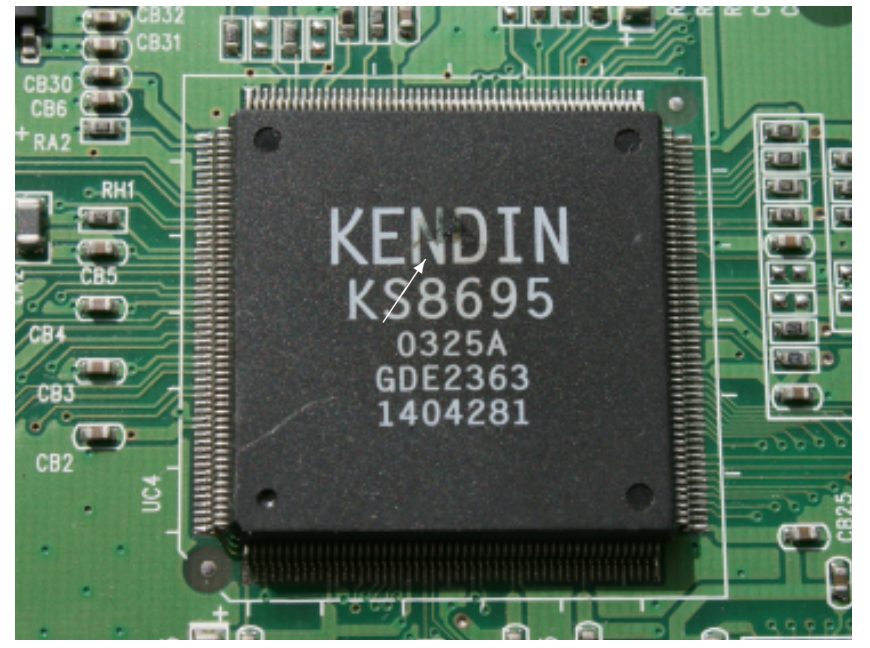

Fig. 4. An LSI circuit's package cracking at $800 \mathrm{~W}$ for 8 s time irradiation.

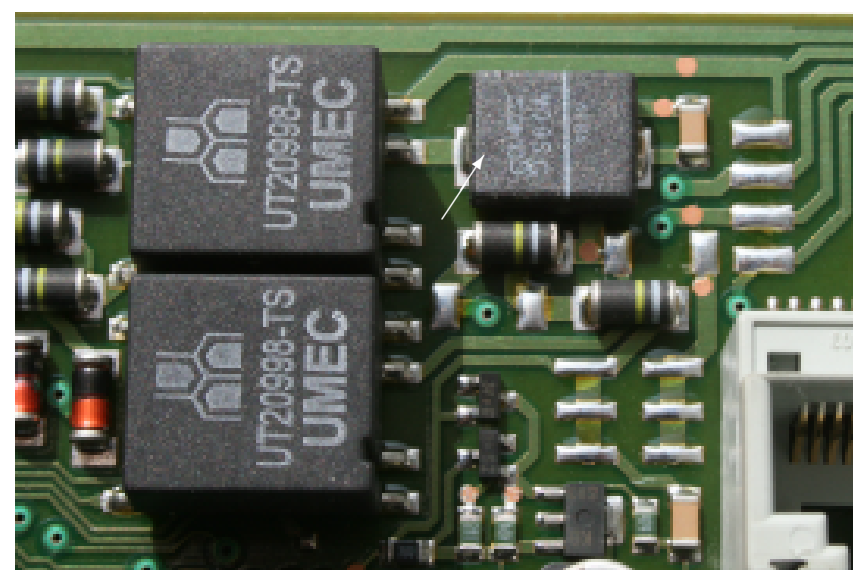

Fig. 5. CU4032 type voltage-dependent resistance package cracking at $800 \mathrm{~W}$ for $5 \mathrm{~s}$ time irradiation.

devices are between $400 \mathrm{~W}$ and $1,2 \mathrm{~kW}$ or can be adjustable [8]. according equation (1);

$$
\lambda_{\mu W}=\frac{v_{l}}{f_{\mu W}} n
$$

where; $\lambda_{\mu W}$ is wavelength of radiation of microwave-oven, $v_{l}$ is the about speed of light. In the next, we'll work with a half-wave dipole as the most effective antenna. This value in actual frequency, from equation (1) is $\sim 12 \mathrm{~cm}$.

For the experimental presentation of the effect, various quasicalculated antennas were prepared (Fig.6). In Fig.7 is seen folia-structure of Fig.6 after 800W, 4 seconds microwave irradiation.

\section{Possible Electronic-Circuit Solutions}

In the following, we will present the possible pragmatic solutions. Our main facets are the simple implementation of commercial parts, the cheapest solution, the irreversible change that is clearly and easily detectable. It takes as few spaces as possible.
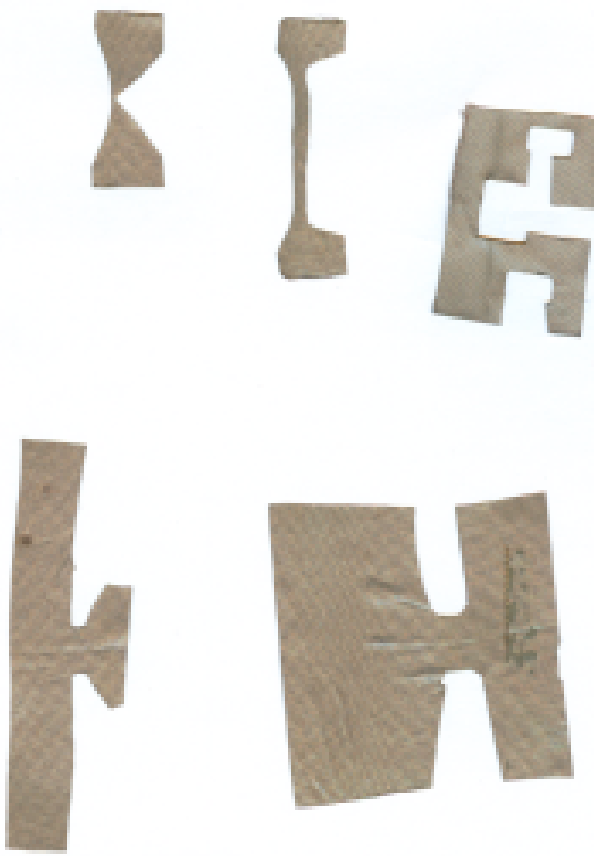

Fig. 6. Quasi-adjustable microwave Al-folia antenna on paper, for spark gap experiments, before the microwave irradiation.

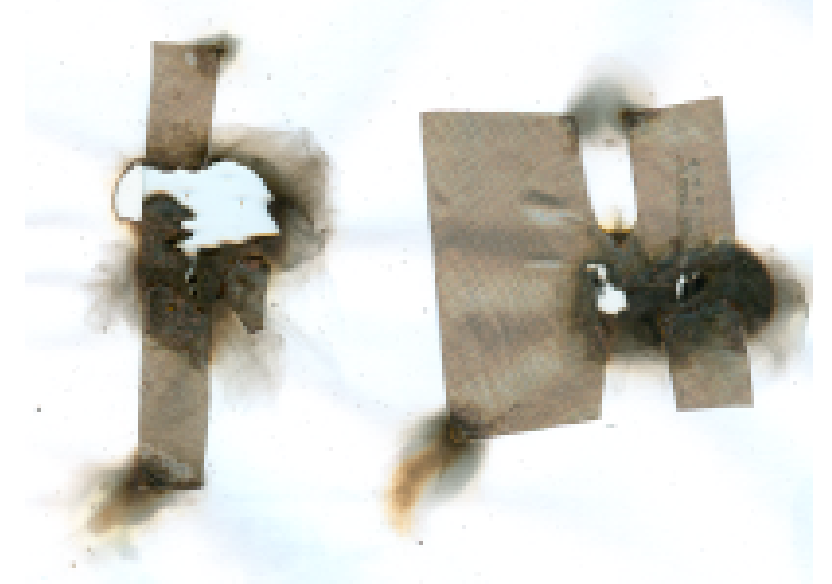

Fig. 7. Burning damage at $800 \mathrm{~W}$ microwave power $2 \mathrm{~s}$ long irradiation. 

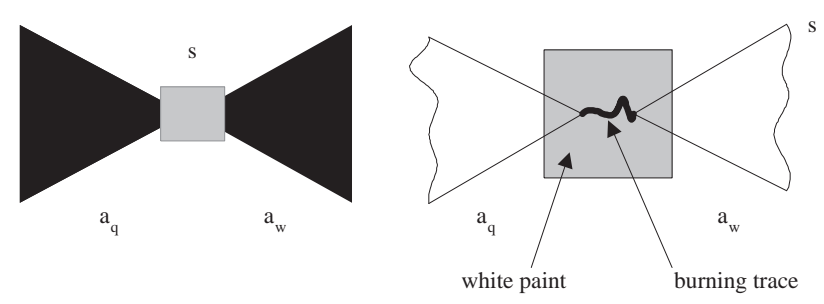

Fig. 8. The microwave antenna (left) and the spark gap (right) with burning trace.

\section{A. Spark-Gap}

The half-wave dipole, space-saving or surface-saving practical reasons can be approached with a trap antenna (Fig.8). The antenna consist of two element; $a_{q}, a_{w}$, which are formed from the 17,5 $\mu \mathrm{m}$ thick copper foil of the printed circuit board. There are about $1 \mathrm{~mm}$ between the two elements of antenna, this is the spark gap. The spark that may be generated, leaving a clear burning mark $(s)$ on the paint. [7]

\section{B. Resistor}

On Fig. 9 is seen such solution when we use a resistor $\left(R_{S}\right)$ between two pole $\left(a_{q}, a_{w}\right)$ of trap antennas. Value of resistance $\left(R_{S}\right)$ is equal of wave impedance; $\left(R_{s}=Z_{0}\right)$, where $Z_{0}$ is output impedance of trap antennas.

There are two kinds of damage to the resistor in this case; electrical breaks $\left(R_{s 0}\right)$ or short circuit conductivity $\left(R_{s c}\right)$. Both cases can be easily checked using an Ohm-meter.[17] [15]
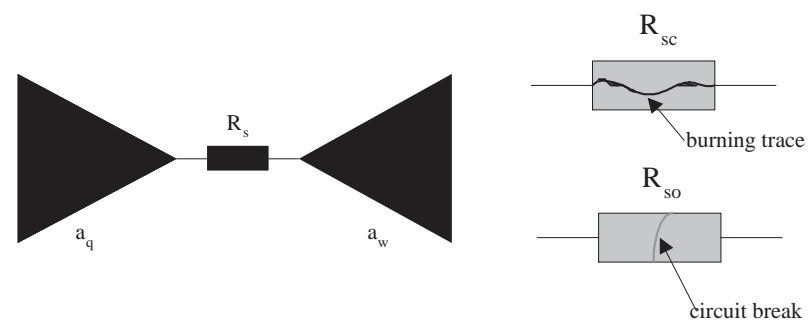

Fig. 9. Low power resistance, such as a microwave-damaged component.

\section{Diode}

Fig. 10 shows that solution when we use a diode for sensing an extra great microwave irradiation. In this case we have opportunity for create a big sensitivity arrangement. For this need application of Schottky-diode [2]. Damage of semiconductor two, earlier described, kind able. The detectable failure of the semiconductor may be two, earlier described types $\left(D_{s c}, D_{s 0}\right)$.

\section{Low Power Bulb Lamp}

Similarly to the foregoing, we select an element where high energy microwave irradiation can be clearly demonstrated. For this purpose, a low-powered bulb lamp $\left(L_{s}\right)$ is excellent Fig. 11. Its operation is understandable. If it is operated with too
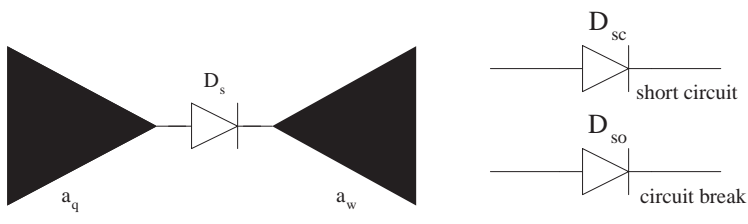

Fig. 10. Semi-conductor diode, such as an microwave-damaged component.

high electrical power, the lamp will burn out $\left(L_{s} 0\right)$. Detection of this can be done here. It is a more elegant solution when the bulb is functionally controlled. With generator drive, with normal operating parameters, visually inspected.

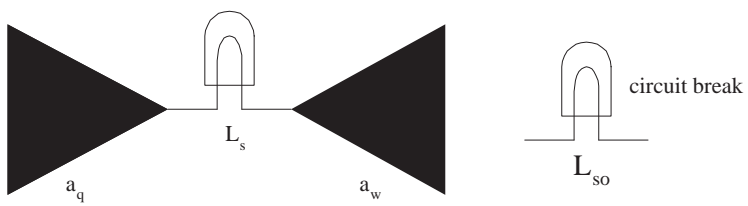

Fig. 11. Light bulb as a as a microwave-damaged component.

\section{E. Fuse}

On Fig. 12 can follow the arrangement of this solution. The function of the fuse in this application is physically equivalent at the bulb described; $\left(F_{s} \rightarrow F_{s 0}\right)$, electronic conductor function changed to electronic break.[5] [4]
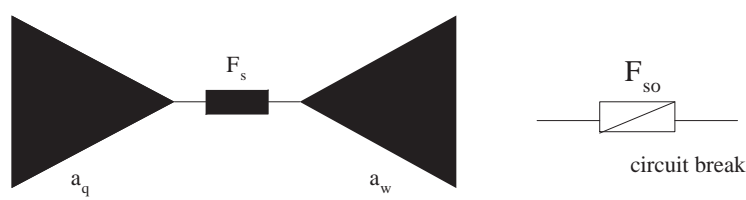

Fig. 12. Fuse as an microwave-damaged component.

\section{TeChnology Aspects}

The solutions described have common symmetrical dipole (trap) antenna, preferably with output impedance fitting. The antenna itself can be made from the copper foil of the printed circuit board at the cheapest, though not small, surface. The recommended electronic components are SMD type.

Space saving is the solution when making a self-adhesive foillike device that can be attached to the inside surface of the equipment. [14] [16]

Until now we have proposed symmetrical antennas. It may also be useful to use an asymmetric antenna ( $a_{s}$ of Fig. 13) for a large, long wire, for example ground-potential $\left(a_{g}\right)$.

\section{Conclusions, Future Work}

The engineer is full of skepticism when he writes an existing incorrect phenomenon and thus formulates the antitheism of his own intent. However, I am convinced that somehow it has to be protected against the phenomenon [3]. In the near future, manufacturers will have a strong expectation. [17] [1] 


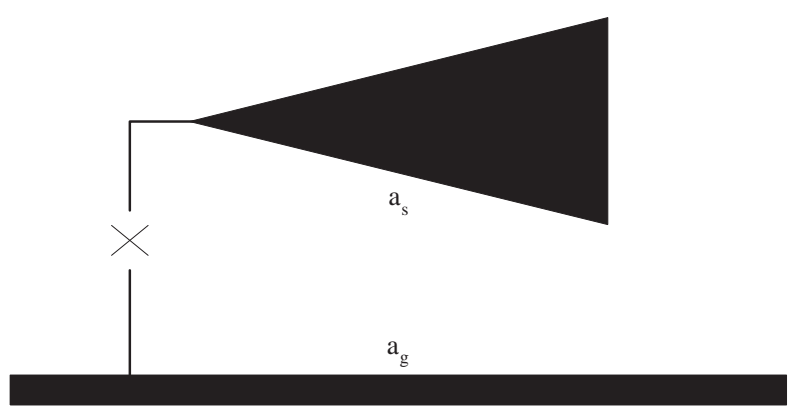

Fig. 13. Antenna $\left(a_{s}\right)$ constructed in relation to the large equipotential $\left(a_{g}\right)$ surface.

An interesting developmental requirement is the development of circuitry solutions that can electronically ask about the parameter of an irreversible change. [13]

The choice of specific, large series solutions is the next development phase. With many measurements, simulations and ready-made designs. [10]

\section{ACKNOWLEDGMENTS}

This research was carried out with the support of the innovation proposal of the University of buda, in Alba Regia Faculity.

\section{REFERENCES}

[1] N. Ádám. Single input operators of the df kpi system. Acta Polytechnica Hungarica, 7(1):73-86, 2010.

[2] J. Hurtuk B. Mados, N. Adam and M. Copjak. Brain-computer interface and Arduino microcontroller family software interconnection solution. 2016 IEEE 14th International Symposium on Applied Machine Intelligence and Informatics (SAMI), ISBN 978-1-4673-8739-2, pp. 217-221, Herlany, 2016.

[3] Gy. Györök, M. Makó, J. Lakner. Combinatorics at electronic circuit realization in FPAA. Acta Polytechnica Hungarica, Journal of Applied Sciences, 6(1):151-160, 2009.

[4] Gy. Györök. The function-controlled input for the IN CIRCUIT equipment. Proc. 8th Intelligent, Engineering Systems Conference (INES2004), pages 443-446, September 2006.

[5] Gy. Györök. Self configuration analog circuit by FPAA. Proc. 4th Slovakien-Hungarien Joint Symposium on Applied Machine Intelligence (SAMI2006), pages 34-37, January 2006.

[6] Gy. Györök. Self organizing analogue circuit by monte carlo method. Proc. IEEE International Symposium on Logistics and Industrial Informatics (LINDI2007), pages 34-37, September 2007.

[7] Gy. Györök. A-class amplifier with FPAA as a predictive supply voltage control. Proc. 9th International Symposium of Hungarian Researchers on Computational Intelligence and Informatics (CINTI2008), pages 361368, November 2008.

[8] Gy. Györök. The FPAA realization of analog robust electronic circuit. Proc. IEEE Internacional Conference on Computational Cybernetics (ICCC2009), pages 1-5, November 2009.

[9] Gy. Györök. Crossbar network for automatic analog circuit synthesis. Proceedings (Liberios Vokorokos, Ladislav Hluch, Jnos Fodor szerk.) of the IEEE 12th International Symposium on Applied Machine Intelligence and Informatics (SAMI 2014). IEEE Computational Intelligence Society, Budapest: IEEE Hungary Section, ISBN:978-1-4799-3441-6, pages 263267, January 2014.

[10] J. Kopják. Dynamic analysis of distributed control network based on event driven software gates. IEEE 11th International Symposium on Intelligent Systems and Informatics, Subotica, Serbia, ISBN: 978-14673-4751-8:p. 293-297, 2013.

[11] R. Kovacs L. Fozo, R. Andoga. Thermo-dynamic cycle computation of a micro turbojet engine. IEEE, Óbudai Egyetem, ISBN 978-1-50903909-8, Budapest, 2016.
[12] R. Andoga M. Komjty, L. Fozo. Experimental identification of a small turbojet engine with variable exhaust nozzle. IEEE, CINTI 2015, ISBN 978-1-4673-8519-0, Budapest, 2015.

[13] L. Madarász and Fözö R. Intelligent technologies in modelling and control of turbojet engines. New Trends in Technologies : Control, Management, Computational Intellingence and Network Systems, Rijeka, Croatia, ISBN 978-953-307-213-5:p. 17-38, 2011.

[14] T. Orosz. Analysis of sap development tools and methods. 15th IEEE International Conference on Intelligent Engineering Systems (INES), pages pp. 439-443, 2011.

[15] L. Madarasz T. Karol R. Andoga, L. Fozo. A Digital Diagnostic System for a Small Turbojet Engine. Acta Polytechnica Hungarica, Vol. 10, no. 4, p. 45-58, ISSN 1785-8860, Budapest, 2013.

[16] A. Selmeci and T. Orosz. Usage of soa and bpm changes the roles and the way of thinking in development. IEEE 10th Jubilee International Symposium on Intelligent Systems and Informatics (SISY), pages pp. 265-271, 2012.

[17] L. Vokorokos, N. Ádám, and B. Madol. The process control for $\mathrm{p}$ single operators. 19th International Workshop on Robotics in AlpeAdria-Danube Region, RAAD 2010 - Proceedings, pages 119-123, 2010. 